\title{
miRNA polymorphisms (miR-146a, miR-149, miR-196a2 and $m i R-499)$ are associated with the risk of coronary artery disease
}

\author{
JUNG-HOON SUNG ${ }^{1}$, SANG-HOON KIM ${ }^{1}$, WOO-IN YANG ${ }^{1}$, WON-JANG KIM ${ }^{1}$, \\ JAE-YOUN MOON $^{1}$, IN JAI KIM ${ }^{1}$, DONG-HUN CHA ${ }^{1}$, SEUNG-YUN CHO ${ }^{1}$, JUNG OH KIM ${ }^{2}$, \\ KYEONG AH KIM ${ }^{2}$, OK-JOON KIM ${ }^{3}$, SANG-WOOK LIM ${ }^{1 *}$ and NAM-KEUN KIM ${ }^{2 *}$ \\ ${ }^{1}$ Department of Cardiology, CHA Bundang Medical Center, CHA University, Seongnam, Gyeonggi 463-712; \\ ${ }^{2}$ Department of Biomedical Science, College of Life Science, CHA University, Seongnam, Gyeonggi 463-400; \\ ${ }^{3}$ Department of Neurology, CHA Bundang Medical Center, CHA University, Seongnam, Gyeonggi 463-712, Republic of Korea
}

Received September 15, 2015; Accepted June 1, 2016

DOI: $10.3892 / \mathrm{mmr} .2016 .5495$

\begin{abstract}
Small non-coding microRNAs (miRNAs) are not only important for heart and vascular development but are also important in cardiovascular pathophysiology and diseases, such as ischemia and atherosclerosis-related diseases. However, the effect of miR-146a, miR-149, miR-196a2 and $m i R-499$ polymorphisms on coronary artery disease (CAD) susceptibility remain unknown. The aim of the present study was to examine the genotype frequencies of $m i R-146 a$, $m i R-149, m i R-196 a 2$ and miR-499 polymorphisms in patients with CAD, and assess their clinical applications for diagnosing and monitoring CAD. Using polymerase chain reaction-amplified DNA, microRNA polymorphisms were analyzed in 522 patients with CAD and 535 control subjects. The miR-149 rs2292832 C >T and miR-196a2 rs11614913 T>C polymorphisms were shown to be significantly associated with CAD prevalence. In subgroup analyses according to disease severity, the miR-146a rs2910164GG genotype was significantly associated with CAD risk in the stent $\geq 2$ group. In addition, miR-146aG/-149T/-196a2C/-499 G allele combination was significantly associated with $\mathrm{CAD}$ prevalence (G-T-C-G and G-C-C-G of miR-146a/-149/-196a2/-499). The combination genotypes of $m i R-146 a \mathrm{GG} / 149 \mathrm{TC}+\mathrm{CC}$
\end{abstract}

Correspondence to: Professor Nam-Keun Kim, Department of Biomedical Science, College of Life Science, CHA University, 335 Pangyo-ro, Bundang-gu, Seongnam, Gyeonggi 463-400, Republic of Korea

E-mail: nkkim@cha.ac.kr; namkkim@naver.com

Professor Sang-Wook Lim, Department of Cardiology, CHA Bundang Medical Center, CHA University, 351 Yatap-dong, Bundang-gu, Seongnam, Gyeonggi 463-712, Republic of Korea

E-mail:swlim@cha.ac.kr

*Contributed equally

Key words: coronary artery disease, microRNA, polymorphism, risk factor, haplotype, combined genotype and $m i R-149 \mathrm{CC} / 196 \mathrm{a} 2 \mathrm{TC}$ were significantly associated with CAD incidence. In subgroup analyses, $m i R-146 a$ rs 2910164 $\mathrm{C}>\mathrm{G}$ increased the risk of developing $\mathrm{CAD}$ in non-smoking, hypertensive and nondiabetic subgroups. Furthermore, $m i R-149$ rs2292832 $\mathrm{C}>\mathrm{T}$ and $m i R-196 a 2$ rs11614913 $\mathrm{T}>\mathrm{C}$ was shown to increase CAD risk in females and patients aged $>63$ years old. The $m i R-149 \mathrm{~T}$ allele, $m i R-196 a 2 \mathrm{C}$ allele and $m i R-146 a \mathrm{G} /-149 \mathrm{~T} /-196 a 2 \mathrm{C} /-499 \mathrm{G}$ allele combination were associated with CAD pathogenesis. The combined effects of environmental factor and genotype combination of miRNA polymorphisms may contribute to CAD prevalence.

\section{Introduction}

Cardiovascular disease is the single most prevalent health problem. It is associated with the highest rates of mortality and morbidity worldwide, accounting for $>14 \%$ of all fatalities, and is predicted to remain so until 2030 (1). Coronary artery disease (CAD) is the most common type of cardiovascular disease, in which a plaque builds up inside the coronary arteries that can lead to a complete blockage of blood flow to the heart, resulting in a heart attack. Moreover, plaque build up narrows coronary arteries, which results in decreased blood flow to the heart that can cause chest pain (angina), shortness of breath, or other symptoms. Previous epidemiological studies have identified the role of several modifiable and non-modifiable risk factors in the pathogenesis and prognosis of CAD, including age, gender, smoking, obesity, diet, life style, and genetic factors (2).

One of the major challenges in cardiovascular disease is the identification of reliable clinical biomarkers that can be routinely measured in blood plasma. MicroRNAs (miRNAs), hold promise as novel biomarkers for clinical diagnosis and can be found in a number of bodily fluids, including blood, urine, saliva, plasma and serum. They are protected from degradation in the circulation through association with lipids, proteins or microparticles, rendering them an attractive disease biomarker candidate (3). miRNAs are short non-coding RNA sequences that regulate the expression of multiple target genes, predominantly by binding to the 3'-untranslated region of mRNA transcripts, resulting either in translational inhibition 
or mRNA degradation (4). In the cardiovascular system, miRNAs are not only important for heart and vascular development but are also essential in cardiovascular pathophysiology and cardiovascular diseases, such as arrhythmia, ischemia and coronary atherogenesis (5). miRNAs have been increasingly implicated in the control of various biological processes, including cell differentiation, cell proliferation, cell growth and apoptosis, and numerous pathological processes, such as cancer, Alzheimer's disease and cardiovascular disease (3). Polymorphic miRNA-mediated gene regulation and mutations in the corresponding sequence space (machinery, miRNA precursors and the target sites) are likely to make a significant contribution to phenotypic variation, including the susceptibility to diseases, such as cancer and cardiovascular disease (6). A single nucleotide polymorphism (SNP) is a DNA sequence variation of a single nucleotide, adenine (A), thymine $(\mathrm{T})$, cytosine $(\mathrm{C})$ or guanine $(\mathrm{G})$, on genomic DNA. An SNP in an miRNA sequence may alter miRNA expression and/or maturation and have been shown to be associated with the progression of CAD. $m i R-146 a \mathrm{G}>\mathrm{C}, m i R-149 \mathrm{C}>\mathrm{T}$, $m i R-196 a 2 \mathrm{~T}>\mathrm{C}$ and $m i R-499 \mathrm{~A}>\mathrm{G}$ polymorphisms have been reported to be associated with lung, breast, thyroid, colon and gastric cancer (7). Recently, four well-known miRNA polymorphisms in pre-miRNA sequences [miR-146aC $>\mathrm{G}$ (rs2910164; chromosome 5, 159912418), $m i R-149 \mathrm{~T}>\mathrm{C}$ (rs2292832; chromosome 2, 241395503), miR-196a2T >C (rs11614913; chromosome 12, 54385599) and $m i R-499 \mathrm{~A}>\mathrm{G}$ (rs3746444; chromosome 20, 33578251)] have been investigated in a variety of diseases and were found to contribute to pathogenesis (8).

In particular, significantly increased levels of miR-146a (6.25-fold) compared with controls and patients with the wild type variant were associated with the CC genotype in patients with CAD $(\mathrm{P}<0.0001)(9)$. hsa-miR-149 may be involved in congenital heart disease by regulating methylenetetrahydrofolate reductase (MTHFR), but which can be altered by regulation of MTHFR, because the binding site has an rs4846049 polymorphism in the MTHFR 3'-untranslated region (10). In addition, it has been suggested that the plasma $m i R-499$ concentration may be a biomarker of myocardial infarction in humans $(11,12)$. Further follow-up case-control studies, identified two SNPs (rs11614913 and rs3746444) in hsa-miR-196a2 and hsa-miR-499 that are associated with an increased risk of developing cancer (13-15), congenital heart disease (16) and dilated cardiomyopathy. Thus, it was hypothesized that SNPs in these miRNAs may also contribute to susceptibility to and unfavorable prognosis of CAD.

According to recent data, the $m i R-146 a \mathrm{G}, m i R-149 \mathrm{~T}$, $m i R-196 a 2 \mathrm{C}$ and $m i R-499 \mathrm{G}$ alleles are possible genetic predisposing factors in various diseases (17-19). Moreover, these four miRNAs have been shown to affect vascular damage responses, such as those in abortion, cancer, ischemic stroke and cardiovascular disease $(8,17,18,20,21)$. The $m i R-146 a,-149$, $-196 a 2$ and -499 alleles are closely associated with the regulation of tumor necrosis factor- $\alpha$ (TNF- $\alpha)$, MTHFR, Annexin A1 (ANXA1), and C-reactive protein (CRP), respectively (8). Furthermore, in the circulatory system, these miRNA targets are important in thrombosis and inflammatory signaling pathways. Recent advances in genetic research have systematically identified and analyzed human polymorphisms in miRNAs and/or miRNA target sites $(22,23)$. However, the majority of these studies focus on SNPs in the target sites and their effects on disease-related miRNAs $(8,22-24)$. One of these studies has mentioned the interplay effects between miRNAs' SNP and target gene SNPs in disease (24). There are currently no data regarding the role of miRNA polymorphisms in CAD pathogenesis. Therefore, the present study aimed to investigate a miRNA-miRNA synergistic effect associated with CAD by genetic association analyses of these four well known miRNA variants and CAD patients, with or without percutaneous coronary intervention (PCI) according to disease severity.

\section{Materials and methods}

Study population. The study subjects were recruited from the South Korean provinces of Seoul and Kyeonggi-do between 2006 and 2015 from the Department of Cardiology at the CHA Bundang Medical Center in Seongnam, South Korea. The study was approved by the Institutional Review Board of CHA Bundang Medical Center (Seongnam, Korea). In total, 522 patients with CAD were referred from the Department of Cardiology at CHA Bundang Medical Center, CHA University. All patients who presented with stable coronary artery disease or acute coronary syndromes (including unstable angina with or without ST-segment elevation) and at least one coronary lesion with $>50 \%$ stenosis in a vessel with a diameter of 2.25-4.00 mm between 2006 and 2015, were screened for eligibility. No restrictions were placed on the total number of treated lesions, which vessels were treated, lesion length, or the number of stents implanted. Exclusion criteria were history of acute myocardial infarction and life expectancy $<1$ year. All patients underwent coronary angiography and electrocardiography. Diagnoses were made by coronary angiography, and were confirmed by at least 1 independent experienced cardiologist.

In total, 535 gender- and age ( \pm 5 years)-matched control subjects from patients presented at the Department of Cardiology at the CHA Bundang Medical Center (Seongnam, Korea) during the same period for health examinations, including biochemical testing, electrocardiograms, and coronary computed tomography scans. Exclusion criteria were the same as those used in the patient group, as well as a recent history of anginal symptoms. Hypertension was defined as systolic pressure $>140 \mathrm{mmHg}$ and diastolic pressure $>90 \mathrm{mmHg}$ on $>1$ occasion and included patients currently taking hypertensive medications. Diabetes mellitus was defined as a fasting plasma glucose level $>126 \mathrm{mg} / \mathrm{dl}(7.0 \mathrm{mmol} / \mathrm{l})$ and included patients taking diabetic medications. Smoking refers to patients who currently smoke. Hyperlipidemia was defined as a high fasting serum total cholesterol (TC) level ( $\geq 240 \mathrm{mg} / \mathrm{dl}$ ) or an antihyperlipidemic agent treatment history.

Genetic analyses. DNA was extracted from peripheral blood leukocytes using the G-dex II Genomic DNA Extraction kit (iNtRON Biotechnology, Inc., Seongnam, Korea), according to the manufacturer's instructions. Polymerase chain reaction (PCR) restriction fragment length polymorphism assays to analyze the $m i R-146 a \mathrm{C}>\mathrm{G}, m i R-196 a 2 \mathrm{~T}>\mathrm{C}$ and $m i R-499 \mathrm{~A}>\mathrm{G}$ polymorphisms. Genotyping of the $m i R-149 \mathrm{~T}>\mathrm{C}$ polymorphism was determined using quantita- 
tive PCR (RG-3000, Corbett Research, Mortlake, Australia) for allelic discrimination. Primers and TaqMan probes were designed using Primer Express Software (version 2.0; Thermo Fisher Scientific, Inc., Waltham, MA, USA), and synthesized and supplied by Applied Biosystems (Foster City, CA, USA). The reporter dyes used were 5-carboxyfluorescein (FAM) and 2',7'-dimethoxy-4',5'-dichloro-6-carboxyfluorescein (JOE). The primer sequences for amplification are as follows: forward: 5'-CAT GGG TTG TGT CAG TGT CAG AGC T-3' and reverse: 5'-TGC CTT CTG TCT CCA GTC TTC CAA-3' for $m i R-146 a \mathrm{C}>\mathrm{G}$; forward: 5'-CTG GCT CCG TGT CTT CAC TC-3' and reverse: 5'-CAA CTC GCC CAG CCG-3' for $m i R-149 \mathrm{~T}>\mathrm{C}$; forward: 5'-CCC CTT CCC TTC TCC TCC AGA TA-3' and reverse: 5'-CGA AAA CCG ACT GAT GTA ACT CCG-3' for miR-196a2T>C; and forward: 5'-CAA AGT CTT CAC TTC CCT GCC A-3' and reverse: 5'-GAT GTT TAA CTC CTC TCC ACG TGA TC-3' for $m i R-499 \mathrm{~A}>\mathrm{G}$. The selected probes were 5'-FAM-TGG GGC AGC CGG AAC AAC-TAMRA-3' (C allele detecting probe) and 5'-JOE-TGG GGC AGC TGG AAC AAC-TAMRA-3' (T allele detecting probe) for $m i R-149 \mathrm{~T}>\mathrm{C}$. Underlined bases in the primers above are mismatches with the complementary sequence. The $m i R-146 \mathrm{aC}>\mathrm{G}$ and $m i R-196 \mathrm{a} 2 \mathrm{~T}>\mathrm{C}$ polymorphisms were digested by $S a c \mathrm{I}$ and $M s p \mathrm{I}$, respectively, for $16 \mathrm{~h}$ at $37^{\circ} \mathrm{C}$ (New England BioLabs, Beverly, MA, USA). The miR-499A $>\mathrm{G}$ polymorphism was digested with $\mathrm{Bcll}$ for $16 \mathrm{~h}$ at $50^{\circ} \mathrm{C}$ (New England Biolabs). The PCR conditions were as follows: Initial denaturation at $94^{\circ} \mathrm{C}$ for $5 \mathrm{~min} /$ denaturation at $94^{\circ} \mathrm{C}$ for $30 \mathrm{sec}$; annealing at $58^{\circ} \mathrm{C}$ for $30 \mathrm{sec}$, extension at $72^{\circ} \mathrm{C}$ for $30 \mathrm{sec}$ with 32 amplification cycles/final extension at $72^{\circ} \mathrm{C}$ for $5 \mathrm{~min}$ for the $m i R-146 a \mathrm{G}>\mathrm{C}, m i R-196 a 2 \mathrm{C}>\mathrm{T}$ and $m i R-499 \mathrm{C}>\mathrm{T}$ polymorphisms. The miR-149T $>\mathrm{C}$ was designed for real-time quantitative PCR (RT-qPCR): Initial denaturation at $95^{\circ} \mathrm{C}$ for $15 \mathrm{~min} /$ denaturation at $95^{\circ} \mathrm{C}$ for $30 \mathrm{sec} /$ annealing at $58^{\circ} \mathrm{C}$ for $50 \mathrm{sec}$ with 50 amplification cycles. The reaction product (12 $\mu \mathrm{l}$ ) was run on a $3.0 \%$ ethidium bromide-stained agarose gel and directly visualized under ultraviolet illumination. Approximately $10 \%$ of the PCR assays were randomly repeated for each of the miRNA polymorphisms and the results were checked for concordance by DNA sequencing using an automatic sequencer (ABI 3730x 1 DNA analyzer; Applied Biosystems). The concordance of the quality control samples was $100 \%$.

Statistical analysis. To estimate the relative risk of the various genotypes for $\mathrm{CAD}$, the odds ratio (OR) and $95 \%$ confidence interval (CI) were calculated. Case and control groups were compared using Student's t-test for continuous variables, and the $\chi^{2}$ test for categorical variables. For multivariate analyses, logistic regression analyses were used to adjust for possible confounders, including age, gender, hypertension, Diabetes mellitus, hyperlipidemia and smoking. $\mathrm{P}<0.05$ was considered to indicate a statistically significant difference. Multiple hypotheses testing was performed using the Benjamini-Hochberg method to control for false discovery rate (FDR) in the logistic regression analysis. Calculating the FDR is a way to address the problems associated with multiple comparisons, and FDR provides a measure of the expected proportion of false-positives among data. Analyses were performed using GraphPad Prism 4.0 (GraphPad Software, Inc., San Diego, CA, USA),
StatsDirect Statistical Software Version 2.4.4 (StatsDirect Ltd., Altrincham, UK), and MedCalc (Version 7.4 for Windows; MedCalc, Ostend, Belgium). The multifactor dimensionality reduction (MDR) method was proposed by Ritchie et al (25), and implemented by Hahn et al (26). The MDR method has been described in detail previously $(25,26)$. Briefly, the MDR is comprised of 2 steps. The best combination of multifactors is initially selected and the genotype combinations are classified into high and low-risk groups (26). Interaction analyses were performed in the open-source MDR software package (v.2.0) available from www.epistasis.org. Using MDR analyses, all possible allele combinations were constrcted for gene-gene interactions. HAPSTAT software was used to estimate the frequencies of allele combinations for the polymorphisms selected by MDR analysis with strong synergistic effects. HAPSTAT allows testing of the haplotype (or allele combination) effects by maximizing the likelihood (from the observed data) that properly accounts for phase uncertainty and study design. Current versions of the HAPSTAT software (v.3.0) are available from www.bios.unc.edu/ lin/hapstat/.

\section{Results}

Characteristics of the study population. Baseline characteristics of the CAD patients and controls are shown in Table I. No significant differences in the age and gender distribution were identified between the patients with CAD and controls, suggesting that our frequency-matching on age and gender was satisfactory. The average body mass index (BMI) of CAD patients was significantly higher than that of the controls $(\mathrm{P}<0.0001)$. In addition, the serum total cholesterol (TC) and TG levels were significantly higher and those of high density lipoprotein-cholesterol (HDL-C) were significantly lower in the patients with CAD compared with the controls $(\mathrm{P}=0.022, \mathrm{P}=0.004$ and $\mathrm{P}=0.001$, respectively); however, no difference was identified in the level of serum low density lipoprotein-cholesterol (LDL-C) between the two groups $(\mathrm{P}=0.116)$. For the disease history, 135 (25.9\%) patients had a history of Diabetes mellitus (DM), which was significantly higher compared with controls $(\mathrm{P}=0.0003)$, however, no significant difference was identified in the hypertension history between CAD patients and controls. Furthermore, no significant difference was identified in smoking $(\mathrm{P}=0.165)$, the hyperlipidemia history $(\mathrm{P}=0.226)$, plasma homocysteine (HCY) level $(\mathrm{P}=0.315)$, serum folate level $(\mathrm{P}=0.288)$ and serum vitamin $\mathrm{B} 12$ level $(\mathrm{P}=0.097)$ were shown between $\mathrm{CAD}$ patients and controls.

miR-149 and miR-196a2 polymorphisms are significantly correlated with CAD. miR-146aC $>\mathrm{G},-149 \mathrm{~T}>\mathrm{C},-196 a 2 \mathrm{~T}>\mathrm{C}$, and $-499 \mathrm{~A}>\mathrm{G}$ polymorphisms were investigated and their genotype distributions in CAD patients and control subjects were determined (Table II). The adjusted odds ratio (AOR) from logistic regression analyses with respect to age, gender, hypertension, diabetes mellitus and hyperlipidemia was calculated. The miRNA genotype frequencies of controls were consistent with Hardy-Weinberg equilibrium. The miR-149 rs $2292832 C>T$ polymorphism was significantly different between patients with CAD and control subjects (TT vs. TC: COR, $1.312,95 \%$ CI, 1.018-1.692; AOR, 1.336, 95\% CI, 
Table I. Baseline characteristics between controls and patients with CAD.

\begin{tabular}{|c|c|c|c|}
\hline Characteristic & Controls & CAD patients & P-value \\
\hline $\mathrm{N}$ & 535 & 522 & \\
\hline Age (years, mean \pm SD) & $60.68 \pm 11.59$ & $60.75 \pm 11.61$ & 0.932 \\
\hline Male, n (\%) & $267(50.0)$ & $261(50.0)$ & 0.972 \\
\hline Hypertension, n (\%) & $243(45.4)$ & $227(43.5)$ & 0.736 \\
\hline $\mathrm{SBP}(\mathrm{mmHg}$, mean $\pm \mathrm{SD})$ & $131.65 \pm 17.00$ & $128.46 \pm 22.76$ & 0.010 \\
\hline $\mathrm{DBP}(\mathrm{mmHg}$, mean $\pm \mathrm{SD})$ & $80.64 \pm 11.68$ & $79.09 \pm 13.63$ & 0.048 \\
\hline Diabetes millitus, n (\%) & $79(14.8)$ & $135(25.9)$ & 0.0003 \\
\hline FBS $(\mathrm{mg} / \mathrm{dl})$ & $112.46 \pm 37.37$ & $140.90 \pm 62.24$ & $<0.0001$ \\
\hline $\mathrm{BMI} \geq 25 \mathrm{~kg} / \mathrm{m}^{2}, \mathrm{n}(\%)$ & $124(23.2)$ & $263(50.4)$ & $<0.0001$ \\
\hline $\mathrm{TG}(\mathrm{mg} / \mathrm{dl}$, mean $\pm \mathrm{SD})$ & $140.86 \pm 86.07$ & $158.79 \pm 110.12$ & 0.004 \\
\hline LDL-C (mg/dl, mean \pm SD) & $116.97 \pm 40.17$ & $112.08 \pm 39.52$ & 0.116 \\
\hline HDL-C (mg/dl, mean \pm SD) & $46.72 \pm 14.73$ & $43.65 \pm 11.10$ & 0.001 \\
\hline Smokers $(\%)$ & $150(28.0)$ & $176(33.7)$ & 0.165 \\
\hline Hyperlipidemia (\%) & $122(22.8)$ & $142(27.0)$ & 0.226 \\
\hline $\mathrm{HCY}(\mu \mathrm{mol} / 1$, mean $\pm \mathrm{SD})$ & $9.83 \pm 3.97$ & $10.12 \pm 5.27$ & 0.315 \\
\hline Folate $(\mathrm{nmol} / \mathrm{l}$, mean $\pm \mathrm{SD})$ & $8.99 \pm 8.01$ & $8.38 \pm 9.15$ & 0.288 \\
\hline Vitamin B12 (pg/ml, mean \pm SD) & $753.09 \pm 707.34$ & $906.47 \pm 1327.12$ & 0.097 \\
\hline Total cholesterol $(\mathrm{mg} / \mathrm{dl}$, mean $\pm \mathrm{SD})$ & $192.38 \pm 43.25$ & $186.03 \pm 45.69$ & 0.022 \\
\hline
\end{tabular}

P-values were calculated by a two-sided t-test for continuous variables and $\chi^{2}$ test for categorical variables. Bold indicates significant values. CAD, coronary artery disease; SD, standard deviation; BP, blood pressure, FBS, fasting blood sugar; HTN, hypertension; DM, Diabetes mellitus; BMI, body mass index; TG, triglycerides; LDL/HDL-C, low/high density lipoprotein-cholesterol; HCY, homocysteine.

1.031-1.731). The miR-196a2 rs11614913 T>C polymorphism was significantly different between CAD patients and control subjects (TT vs. TC: COR, 0.736, 95\% CI, 0.558-0.971; TT vs. TC+CC: COR, 0.768, 95\% CI, 0.592-0.996). However, $m i R-146 a$ rs $2910164 \mathrm{C}>\mathrm{G}$, and $m i R-499$ rs3746444A $>\mathrm{G}$ polymorphisms were not significantly different between CAD patients and control subjects (Table II).

Genotype frequencies of the miRNA polymorphisms between $C A D$ patients with/without $P C I$. The $m i R-146 a \mathrm{C}>\mathrm{G},-149 \mathrm{~T}>\mathrm{C}$, $-196 a 2 \mathrm{~T}>\mathrm{C}$, and $-499 \mathrm{~A}>\mathrm{G}$ polymorphisms in CAD patients with or without PCI and in control subjects was determined. The incidence of the $m i R-146 a$ rs $2910164 \mathrm{C}>\mathrm{G}$ polymorphism was significantly different between patients with CAD with a stent and control subjects (CC+CG vs. GG: COR, 1.499, 95\% CI, 1.036-2.169; CC+CG vs. GG: AOR, 1.473, 95\% CI, 1.005-2.159), and between CAD patients without stent and control subjects (CC vs. GG: COR, 0.531, 95\% CI, 0.282-0.998, AOR, 0.517, 95\% CI, 0.267-1.000; CC+CG vs. GG: COR, 0.495, 95\% CI, 0.272-0.900; CC+CG vs. GG: AOR, 0.479, 95\% CI, 0.258-0.891). The miR-149 rs2292832 C>T polymorphism was significantly different between CAD patients with a stent and control subjects (TT vs. TC: COR, 1.392, 95\% CI, 1.042-1.861, AOR, 1.381, 95\% CI, 1.023-1.864; TT vs. TC+CC: COR, 1.338, 95\% CI, 1.015-1.765). However, the miR-196a2 rs11614913 T>C was significantly different between patients with CAD without a stent and control subjects (TT vs. TC: COR, 0.678, 95\% CI, 0.471-0.975, TT vs. CC: COR, 0.510, 95\% CI, 0.308-0.844, AOR, 0.523, 95\% CI, 0.313-0.875; TT vs. TC+CC: COR, 0.630, 95\% CI, 0.446-0.890, AOR, 0.647,
95\% CI, 0.455-0.919; TT+TC vs. CC: AOR, 0.621, 95\% CI, 0.388-0.993). The miR-499 rs3746444 A>G polymorphisms were not identified to be significantly different between patients with CAD with or without a stent and control subjects (Table III).

Analysis of the number of stents after PCI according to disease severity. To examine whether the effect of each polymorphism is related to the number of implanted stents for a given patient, the patients with stents were group divided into two subgroups $(=1$ and $\geq 2)$ according to disease severity. In subgroup analyses, the miR-146a rs2910164 C>G polymorphism was significantly associated with increased disease severity in the stent $\geq 2$ group (CC vs. GG: COR, 1.875, 95\% CI, 1.013-3.468; CC+CG vs. GG: COR, 1.796; 95\% CI, 1.043-3.094). The miR-149 rs2292832 $\mathrm{C}>\mathrm{T}$ showed significant association with stent $=1$ group (TT vs. CC: COR, 1.399, 95\% CI, 1.011-1.937; TT vs. TC+CC: COR, 1.366, 95\% CI, 1.001-1.863). However, miR-196a2 rs11614913 $\mathrm{T}>\mathrm{C}$, and $m i R-499$ rs3746444 $\mathrm{A}>\mathrm{G}$ polymorphisms were not observed to be significantly different between the 2 subgroups $(=1$ and $\geq 2)$ and control subjects (Table IV).

Subgroup analyses. To determine the additional clinical significance, stratified analyses according to age, gender, hypertension, diabetes mellitus, hyperlipidemia and smoking status. In the stratified analyses, it was demonstrated that the miR-146a rs2910164 C>G polymorphism showed significant increases in the incidence of CAD compared with the CC genotype in the hypertension $(\mathrm{CC}+\mathrm{CG}$ vs. GG: AOR, 1.933, 95\% CI, 1.133-3.298), nondiabetic (CC+CG vs. GG: AOR, 


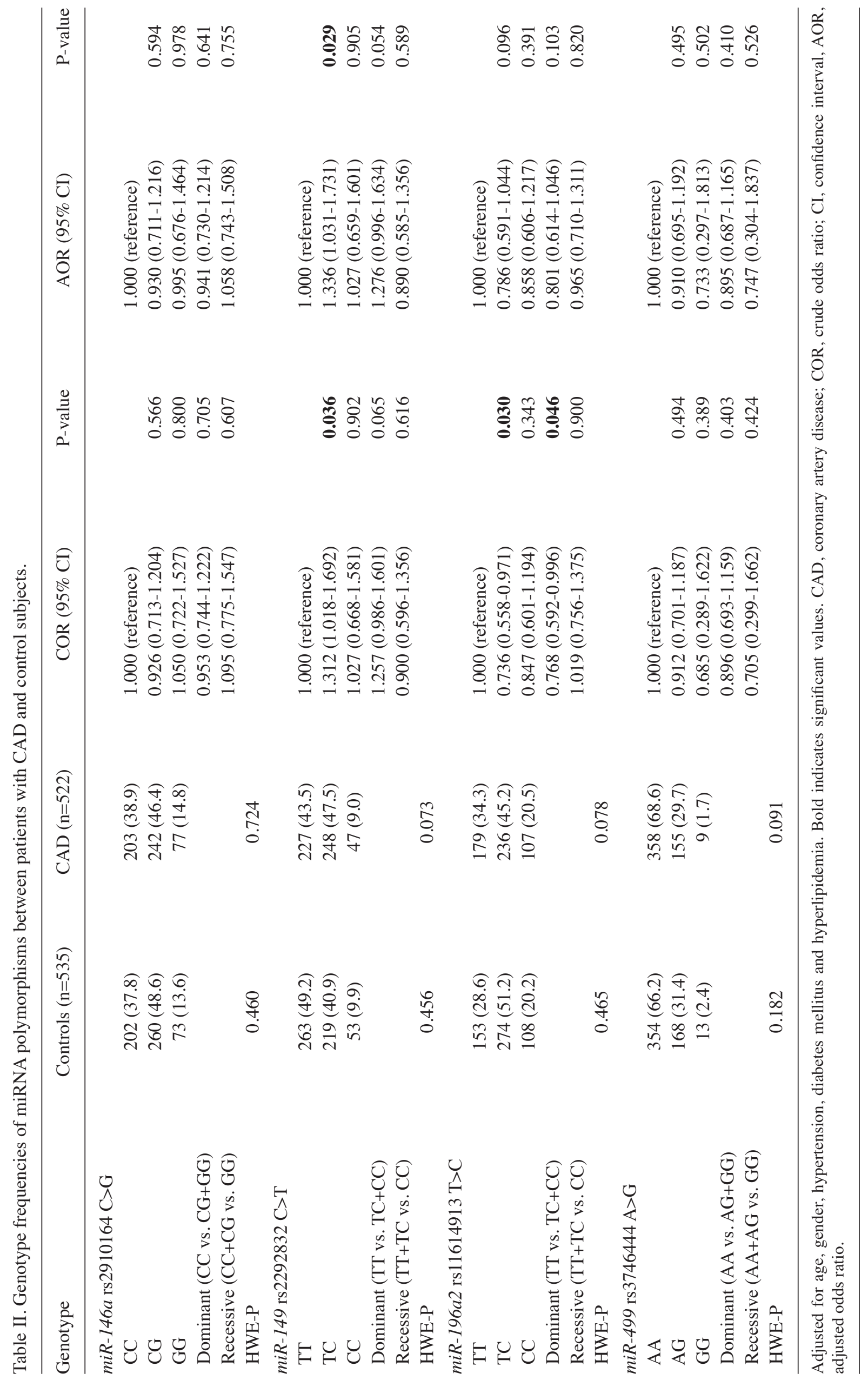




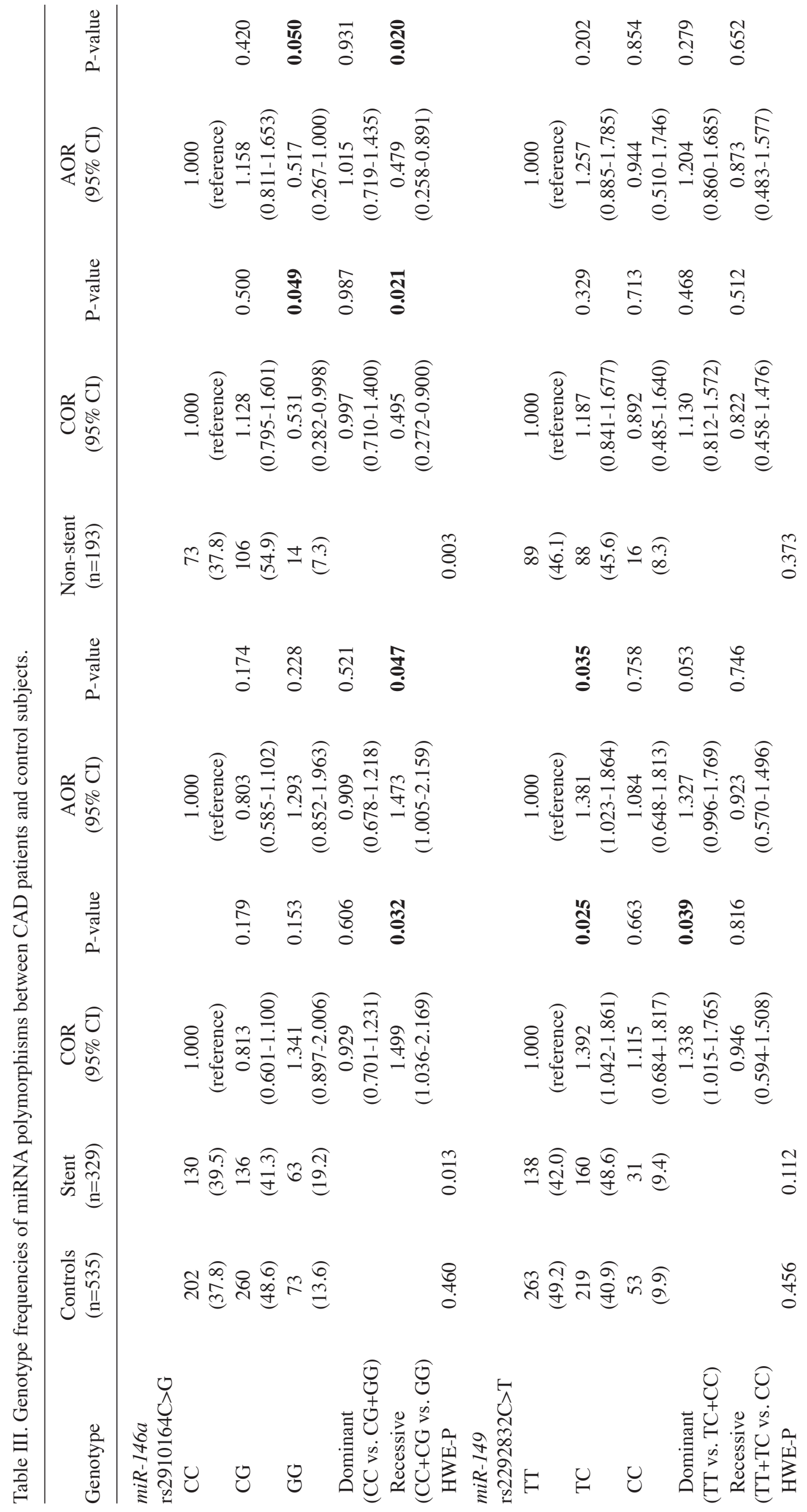




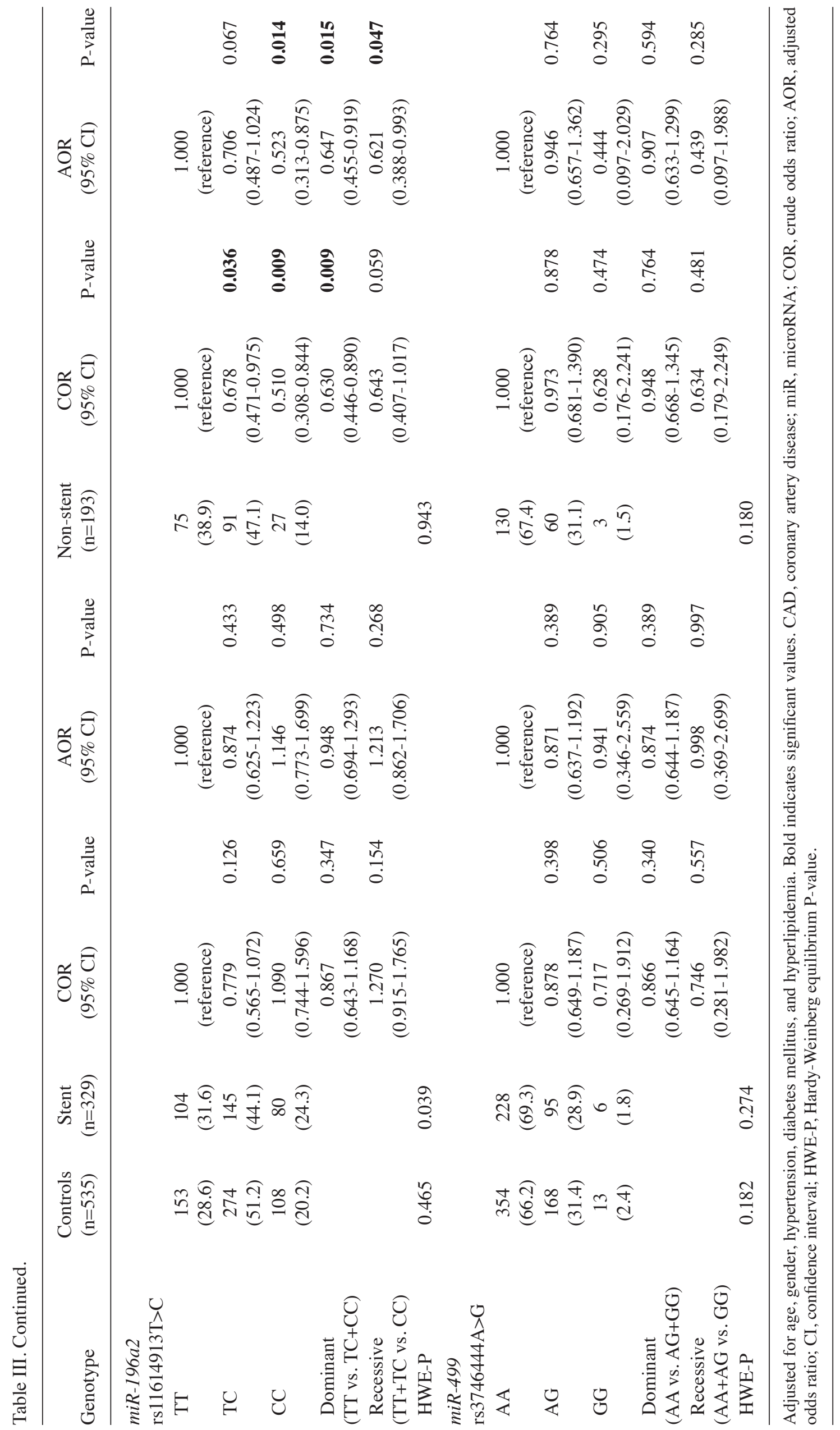




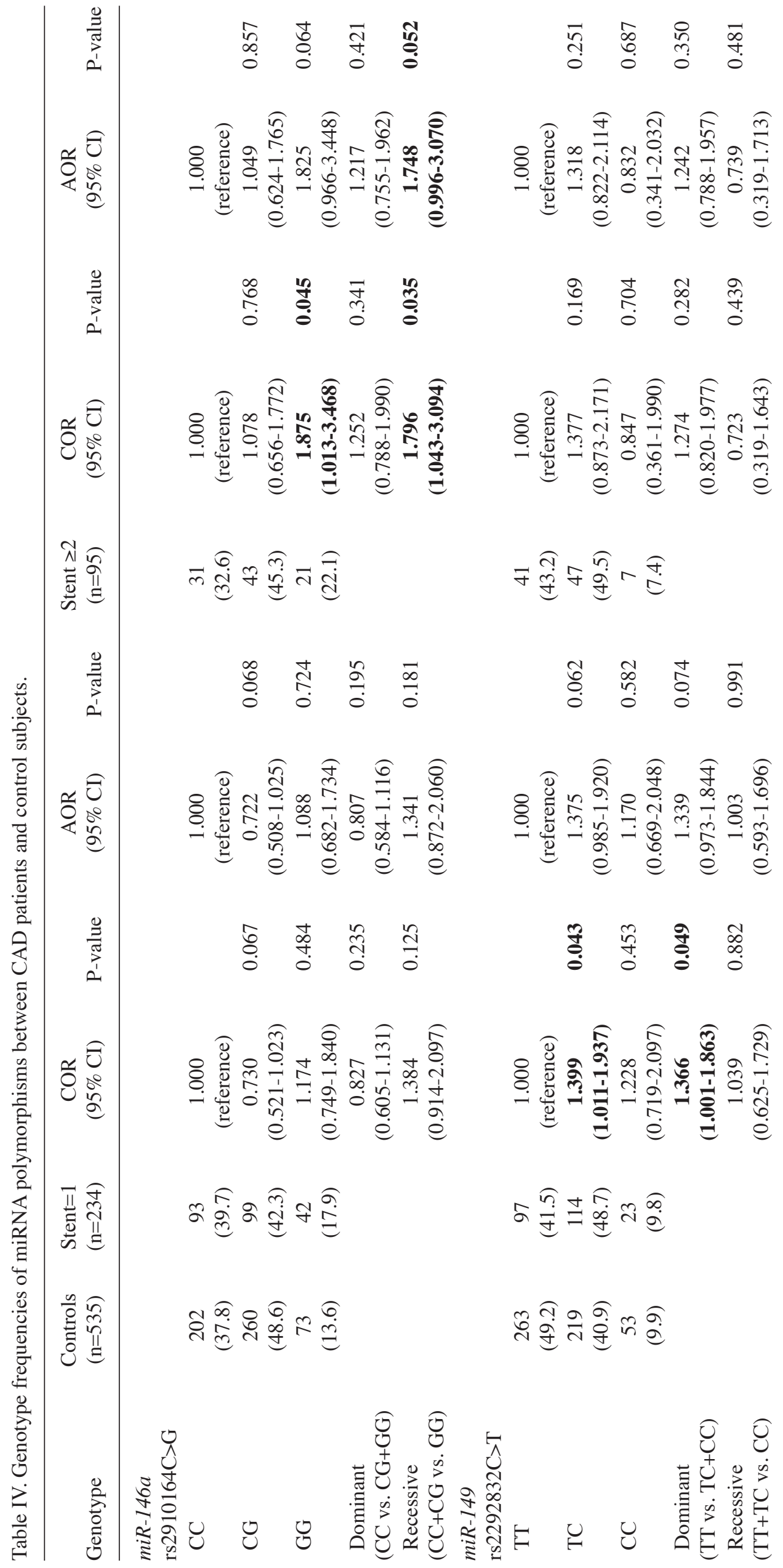




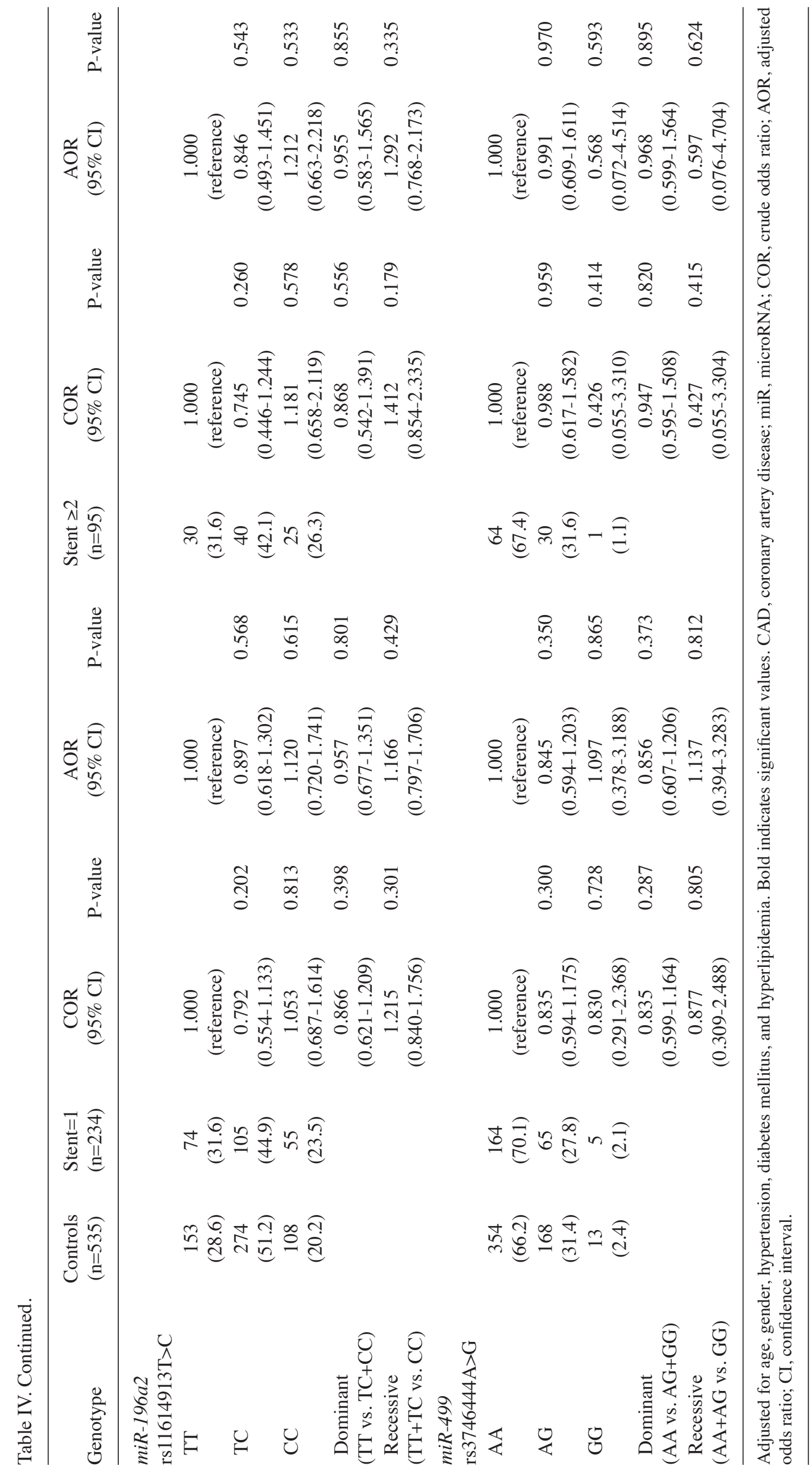


1.619, 95\% CI, 1.047-2.504), and non-smoking subgroups (CC vs. GG: AOR=1.860, 95\% CI, 1.099-3.147). Furthermore, the miR-149 rs2292832 C >T polymorphism showed significant increases in the incidence of CAD compared with the TT genotype in the older age (age $\geq 63$ ) (TT vs. TC: AOR, 1.516, 97\% CI, 1.041-2.209), female (TT vs. TC: AOR, 1.947, 95\% CI, 1.208-3.138; TT vs. TC+CC: AOR, 1.976, 95\% CI, 1.244-3.138) and nonsmoking subgroups (TT vs. TC: AOR, 1.604, 95\% CI, 1.102-2.333; TT vs. TC+CC: AOR, 1.549, 95\% CI, 1.078-2.225; Table V). For CAD, the miR-196a2 rs11614913T>C genotype was associated with a significantly increased risk of CAD in the older subgroup (age $\geq 63$ ) (TT vs. TC: AOR, 0.656, 95\% CI, 0.435-0.988), and female subgroup (TT+TC vs. CC: AOR, 1.860, 95\% CI, 1.097-3.154; Table VI).

Gene-gene interaction analyses using the MDR method. The possible allele combinations of $m i R-146 a, m i R-149$, $m i R-196 a 2$, and $m i R-499$ were constructed to analyze gene-gene interactions (Table VII). As a result, $m i R-146 a / 149$, miR-146a/499, miR-146a/149/196a2, miR-146a/149/499, miR-146a/196a2/499, miR-149/196a2/499, and miR-146a/149/196a2/499 models were selected by the MDR method. Several allele combination frequencies were significantly different between patients with CAD and controls. When patients with CAD were compared with controls, miR-146a/149 (C-T vs. G-C:OR, 1.459, 95\% CI, 1.075-1.981), miR-146a/499 (C-A vs. C-G:OR, 0.707, 95\% CI, 0.507-0.985), miR-146a/149/196a2 (C-T-T vs. G-C-T:OR, 1.713, 95\% CI, 1.136-2.584), miR-146a/149/499 (C-T-A vs. C-T-G:OR, 0.559, 95\% CI, 0.370-0.844), miR-146a/196a2/499 (C-T-A vs. C-T-G:OR, 0.595, 95\% CI, 0.367-0.966), miR-149/196a2/499 (T-T-A vs. T-T-G: OR, 0.603, 95\% CI, 0.387-0.940), and miR-146a/149/196a2/499 (C-T-T-A vs. G-T-C-A: OR, 0.684, 95\% CI, 0.475-0.983; G-T-C-G: OR, 43.55, 95\% CI, 2.575-736.512; G-C-T-G: OR, 3.437, 95\% CI, 1.378-8.572; G-C-C-G: OR, 0.048, 95\% CI, 0.003-0.817) were significantly associated with disease prevalence (Table VII).

Allele combinations of miR-146a, -149, -196a2 and -499 polymorphisms with synergistic effects. To investigate the genes without environmental interaction, the combined effects between miRNA polymorphisms and the prevalence of CAD was analyzed. The AOR from the logistic regression analyses with respect to the age, gender, hypertension, diabetes mellitus and hyperlipidemia was calculated. There were significant combined gene (miR-146a/149) effects when the environmental influence was excluded in CAD risk. (CG/TT: AOR, 0.677,95\% CI, 0.473-0.970; GG/TC: AOR, 1.683, 95\% CI, 1.013-2.797 ; GG/CC: AOR, 4.200, 95\% CI, 1.082-16.306 ; GG/TC+CC: AOR, 1.939, 95\% CI, 1.206-3.118), miR-149/196a2 (CC/TC: AOR, 0.436, 95\% CI, 0.198-0.961; Table VIII).

\section{Discussion}

Circulating miRNAs have many of the essential characteristics to be a good biomarker of noninvasive measurability. For example, a high degree of sensitivity and specificity, which allows the early detection of pathological states, including the time-related changes during the course of disease, a long half-life within the sample, and rapid and cost-effective laboratory detection (22). miRNAs are important in a number of physiological and pathological processes, including tumorigenesis, proliferation, metabolism, immune function and epigenetics (27-30). Emerging evidence has indicated that circulating miRNAs may be biomarkers for cardiovascular diseases, including essential hypertension, heart failure, Diabetes mellitus, stroke, coronary artery disease, acute myocardial infarction and acute pulmonary embolism (15,31-34). To the best of our knowledge, this is the first study to provide evidence that four miRNA polymorphisms are involved in the predisposition to CAD with or without prior PCI. In this study, the $m i R-146 a C>G($ rs2910164), $m i R-149 T>C(\mathrm{rs} 2292832)$, $m i R-196 a 2 T>C(\operatorname{rs} 11614913)$, and $m i R-499 A>G($ rs3746444) polymorphisms were investigated in CAD patients with or without PCI. Furthermore, the results also demonstrated that $m i R-149 T>C(\mathrm{rs} 2292832)$ and $m i R-196 a 2 T>C(\mathrm{rs} 11614913)$ polymorphisms were significantly associated with the development of CAD in females and patients over the age of 63 years old. The results also suggest that the $m i R-146 a C>G$ (rs2910164) polymorphism was significantly associated with hypertension, whereas there was no correlation of the smoking and diabetes mellitus groups with an increased risk of developing CAD. Moreover, the severity of CAD was positively correlated with the number of stents implanted: Patients with CAD that had undergone $\geq 2$ stent treatments showed an increased CAD incidence compared with patients having one stent treatment for the miR-146a rs2910164 C>G polymorphism (Table IV). The precise mechanisms of miRNA-mediated gene expression and maturation are largely unknown; however, studies have suggested several mechanisms, including genetic and epigenetic mechanisms (DNA methylation, histone modification and non-coding RNAs) $(28,35)$. In addition, small variations in the quantity of miRNAs may have an effect on thousands of target mRNAs and result in diverse functional consequences. The most common genetic variations, such as SNPs, in miRNA sequences may also be functional and therefore may represent ideal candidate biomarkers for cancer and cardiovascular diseases, including CAD.

miR-146a, -149, -196a2 and -499 can regulate TNF- $\alpha$, methylenetetrahydrofolate reductase, ANXA1 and CRP, respectively $(10,36,37)$. According to previously published studies, TNF- $\alpha$, methylenetetrahydrofolate reductase, ANXA1, and CRP were well-known risk factors for cerebral ischemia (38-40). TNF- $\alpha$ is associated with increased plasminogen activator inhibitor-1 protein levels (30); methylenetetrahydrofolate reductase dysfunction is associated with plasma total HCY accumulation (29); ANXA1 is connected to decreased TNF- $\alpha$ levels (41); and CRP can elevate blood pressure, body mass index, insulin resistance and TG levels (42). In addition, CRP and TNF- $\alpha$ are simultaneously activated in stress conditions (43). These data suggest that TNF- $\alpha$, ANXA1 and CRP may be closely linked. In fact, MDR analyses in the present study indicated genetic interactions between miR-146a/-196a2/-499 and $m i R-146 a /-196 a 2$. There have been limited studies regarding the functions of miRNA polymorphisms. The $m i R-146 a \mathrm{G}$ and miR-196a2T allele were shown to be associated with decreased mature miRNA levels $(44,45)$. miR-149T>C and $m i R-499 A>\mathrm{G}$ were located in a pre-miRNA structure, not the mature miRNA form. However, these polymorphisms were affected by miRNA biogenesis. In addition, there was no mature miRNA expres- 


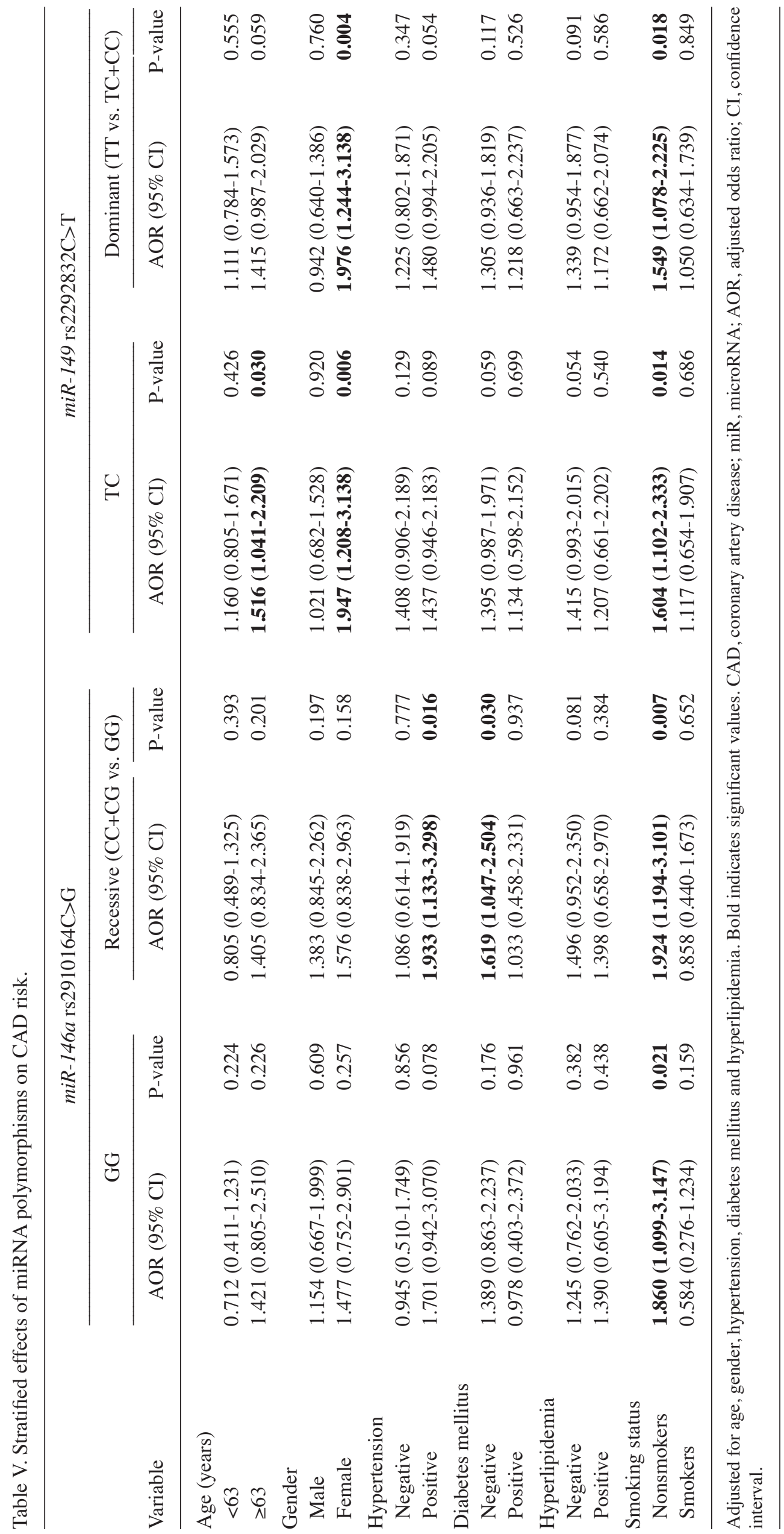




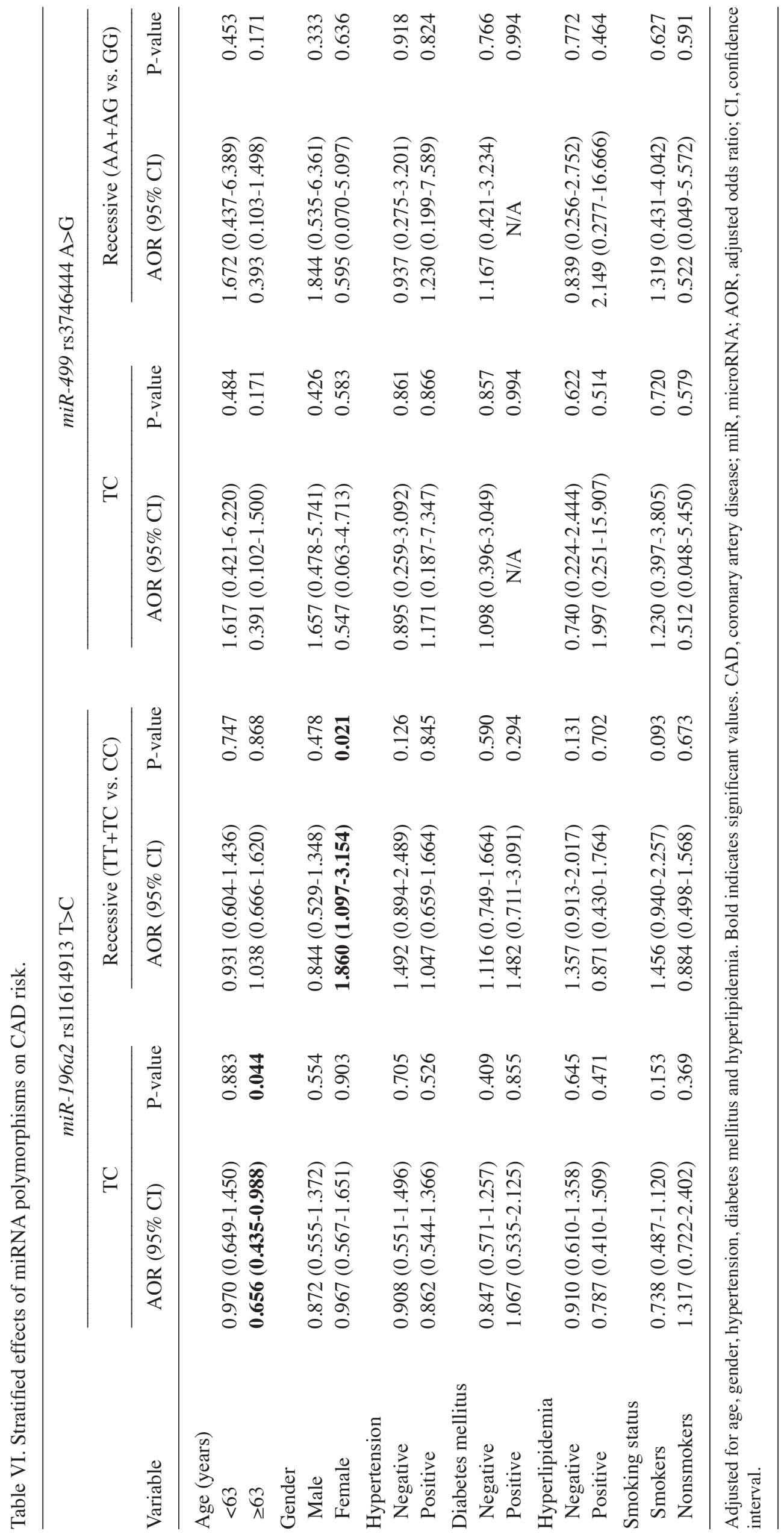


Table VII. Frequencies of $m i R-146 a$, $m i R-149$, miR-196a2 and $m i R-499$ haplotypes in patients with CAD and in controls.

\begin{tabular}{|c|c|c|c|c|c|}
\hline Haplotype & Overall & Control & CAD & OR $(95 \% \mathrm{CI})$ & P-value \\
\hline$m i R-146 a / 149$ & & & & & 0.018 \\
\hline $\mathrm{C}-\mathrm{T}$ & 0.4227 & 0.4240 & 0.4195 & 1.000 (reference) & \\
\hline $\mathrm{G}-\mathrm{C}$ & 0.1258 & 0.1072 & 0.1551 & $1.459(1.075-1.981)$ & \\
\hline$m i R-146 a / 499$ & & & & & 0.042 \\
\hline C-A & 0.4997 & 0.4934 & 0.5087 & 1.000 (reference) & \\
\hline $\mathrm{C}-\mathrm{G}$ & 0.1137 & 0.1272 & 0.0931 & $0.707(0.507-0.985)$ & \\
\hline$m i R-146 a / 149 / 196 a 2$ & & & & & 0.011 \\
\hline $\mathrm{C}-\mathrm{T}-\mathrm{T}$ & 0.2461 & 0.2480 & 0.2427 & 1.000 (reference) & \\
\hline G-C-T & 0.0699 & 0.0541 & 0.0910 & $1.713(1.136-2.584)$ & \\
\hline$m i R-146 a / 149 / 499$ & & & & & 0.006 \\
\hline C-T-A & 0.3441 & 0.3323 & 0.3616 & 1.000 (reference) & \\
\hline $\mathrm{C}-\mathrm{T}-\mathrm{G}$ & 0.0789 & 0.0926 & 0.0561 & $0.559(0.370-0.844)$ & \\
\hline$m i R-146 a / 196 a 2 / 499$ & & & & & 0.038 \\
\hline C-T-A & 0.2830 & 0.2848 & 0.2815 & 1.000 (reference) & \\
\hline $\mathrm{C}-\mathrm{T}-\mathrm{G}$ & 0.0559 & 0.0673 & 0.0392 & $0.595(0.367-0.966)$ & \\
\hline miR-149/196a2/499 & & & & & 0.026 \\
\hline T-T-A & 0.3088 & 0.3052 & 0.3170 & 1.000 (reference) & \\
\hline $\mathrm{T}-\mathrm{T}-\mathrm{G}$ & 0.0685 & 0.0778 & 0.0490 & $0.603(0.387-0.940)$ & \\
\hline \multicolumn{6}{|c|}{ miR-146a/149/196a2/499 } \\
\hline C-T-T-A & 0.2007 & 0.1956 & 0.2107 & 1.000 (reference) & \\
\hline G-T-C-A & 0.1141 & 0.1341 & 0.0992 & $0.684(0.475-0.983)$ & 0.045 \\
\hline G-T-C-G & 0.0158 & 0.0000 & 0.0212 & $43.55(2.575-736.512)$ & $<0.0001$ \\
\hline G-C-T-G & 0.0121 & 0.0068 & 0.0250 & $3.437(1.378-8.572)$ & 0.008 \\
\hline G-C-C-G & 0.0069 & 0.0142 & 0.0000 & $0.048(0.003-0.817)$ & 0.001 \\
\hline
\end{tabular}

Insignificant data were removed from table. Bold indicates significant values. miR, microRNA; CAD, coronary artery disease;OR, odds ratio; CI, confidence interval.

Table VIII. Genotype combination of microRNA polymorphisms.

\begin{tabular}{lccc}
\hline Combined genotype & Controls $(\mathrm{n}=535)$ & CAD $(\mathrm{n}=329)$ & AOR $(95 \%$ CI $)$ \\
\hline miR-146a/149 & $129(24.1)$ & $57(17.3)$ & $\mathbf{0 . 6 7 7}(\mathbf{0 . 4 7 3 - 0 . 9 7 0 )}$ \\
CG/TT & $35(6.5)$ & $35(10.6)$ & $\mathbf{1 . 6 8 3}(\mathbf{1 . 0 1 3 - 2 . 7 9 7 )}$ \\
GG/TC & $3(0.6)$ & $8(2.4)$ & $\mathbf{4 . 2 0 0}(\mathbf{1 . 0 8 2 - 1 6 . 3 1 )}$ \\
GG/CC & $3(0.6)$ & $43(13.1)$ & $\mathbf{1 . 9 3 9 ( 1 . 2 0 6 - 3 . 1 1 8 )}$ \\
GG/TC+CC & $30(5.6)$ & $9(2.7)$ & $\mathbf{0 . 0 3 3}$ \\
miR-149/196a2 & & $\mathbf{0 . 4 3 6}(\mathbf{0 . 1 9 8 - 0 . 9 6 1 )}$ \\
CC/TC & & $\mathbf{0 . 0 3 8}$ \\
\hline Insignificant data were removed from table. Adjusted for age, gender, hypertension, diabetes mellitus and hyperlipidemia. Bold indicates \\
significant values. CAD, coronary artery disease; miR, microRNA; AOR, adjusted odds ratio; CI, confidence interval.
\end{tabular}

sion, according to $m i R-149 \mathrm{~T}>\mathrm{C}$ and $m i R-499 \mathrm{~A}>\mathrm{G}$. However, $m i R-499 \mathrm{AA}$ is associated with decreased plasma CRP concentrations (46). Based on these results, it is hypothesized that $m i R-146 a \mathrm{C}, m i R-196 a 2 \mathrm{~T}$ and $m i R-499 \mathrm{~A}$ alleles have protective roles in vascular pathogenesis through inhibition of TNF- $\alpha$ and CRP levels. However, it was not possible to measure miRNA, TNF- $\alpha$ and CRP levels in the present study.
Recent advances in genetic research have systematically identified and analyzed human polymorphisms in miRNAs and/or miRNA target sites $(2,23)$. However, the majority of these studies focused on SNPs in the target sites and their effects on disease-related miRNAs, while only a few studies have reported the understanding the synergistic regulation of miRNAs and their potential targeted SNPs cooperative 
effects contributing to disease progression. With the rapid identification of disease-related miRNAs, there is a requirement to determine their functional relationships contributing to diseases at a systems biology level.

Data from the present study indicate that specific combinations of miRNA haplotypes are correlated with the incidence of CAD. For example, the G-T-C-G polymorphism of $m i R-146 a / 149 / 196 a 2 / 499$ correlates the most strongly with CAD (OR, 43.55, 95\% CI, 2.575-736.5, P<0.0001), followed by the G-C-C-G (OR, 0.048, 95\% CI, 0.003-0.817, P=0.001) haplotype. The C-T-G polymorphism in $m i R-146 a / 149 / 499$ exhibited the strongest correlation with CAD incidence among all three miRNA haplotypes (OR, 0.559, 95\% CI, 0.370-0.844, $\mathrm{P}=0.006)$. Thus, the specific combination of miRNA polymorphisms appear to provide synergistic effects.

There are several limitations of the present study. It is not yet clear which genetic polymorphisms predict the phenotypes associated with CAD and disease severity. The present study population comprised of only Korean individuals, and these results require validation in other ethnic groups. This was a hospital-based case-control study that had a relatively small sample size. However, the recruitment of $>1,000$ individuals from an ethnically homogeneous population (Koreans have a low degree of interracial marriage) is enough to give reliable data.

In conclusion, the $m i R-146 a \mathrm{C}>\mathrm{G}$ and $m i R-149 \mathrm{~T}>\mathrm{C}$ polymorphisms were associated with an increased risk of CAD in the Korean population. The present study marks the first report of an association between stroke and SBI and miRNA polymorphisms $(m i R-146 a \mathrm{C}>\mathrm{G},-149 \mathrm{~T}>\mathrm{C},-196 a 2 \mathrm{~T}>\mathrm{C}$ and $-499 \mathrm{~A}>\mathrm{G}$ ) in the Korean population. Therefore, additional studies of other racial and ethnic populations regarding the biological functions of miRNA are required to fully understand the role of miRNA polymorphisms in CAD risk.

\section{Acknowledgements}

This study was supported by a National Research Foundation (NRF) of Korea Grant funded by the Korean Government, Ministry of Education (grant no. NRF-2013R1A1A2008177), and supported by a grant of the Korea Health Technology R\&D Project through the Korea Health Industry Development Institute (KHIDI), funded by the Ministry of Health \& Welfare (grant no. HI16C1559), Republic of Korea.

\section{References}

1. World Health Organization: World Health Statistics Report 2008. World Health Organization, Geneva. http://www.who. int/whosis/whostat/2008/en/index.html, 2008.

2. Sullivan PW, Ghushchyan V, Wyatt HR, Wu EQ and Hill JO: Impact of cardiometabolic risk factor clusters on health-related quality of life in the US Obesity (Silver Spring) 15: 511-521, 2007.

3. Zhi H, Wang L, Ma G, Ye X, Yu X, Zhu Y, Zhang Y, Zhang J and Wang B: Polymorphisms of miRNAs genes are associated with the risk and prognosis of coronary artery disease. Clin Res Cardiol 101: 289-296, 2012.

4. Bartel DP: MicroRNAs: Genomics, biogenesis, mechanism, and function. Cell 116: 281-297, 2004.

5. Small EM, Frost RJ and Olson EN: MicroRNAs add a new dimension to cardiovascular disease. Circulation 121: 1022-1032, 2010.

6. Georges M, Coppieters W and Charlier C: Polymorphic miRNA-mediated gene regulation: Contribution to phenotypic variation and disease. Curr Opin Genet Dev 17: 166-176, 2007.
7. Kim WH, Min KT, Jeon YJ, Kwon CI, Ko KH, Park PW, Hong SP, Rim KS, Kwon SW, Hwang SG and Kim NK: Association study of microRNA polymorphisms with hepatocellular carcinoma in Korean population. Gene 504: 92-97, 2012

8. Jeon YJ, Kim OJ, Kim SY, Oh SH, Oh D, Kim OJ, Shin BS and Kim NK: Association of the miR-146a, miR-149, miR-196a2, and miR-499 polymorphisms with ischemic stroke and silent brain infarction risk. Arterioscler Thromb Vasc Biol 33: 420-430, 2013.

9. Ramkaran P, Khan S, Phulukdaree A, Moodley D and Chuturgoon AA: miR-146a polymorphism influences levels of miR-146a, IRAK-1, and TRAF-6 in young patients with coronary artery disease. Cell Biochem Biophys 68: 259-266, 2014.

10. Wu C, Gong Y, Sun A, Zhang Y, Zhang C, Zhang W, Zhao G, Zou Y and Ge J: The human MTHFR rs4846049 polymorphism increases coronary heart disease risk through modifying miRNA binding. Nutr Metab Cardiovasc Dis 23: 693-698, 2013.

11. Adachi T, Nakanishi M, Otsuka Y, Nishimura K, Hirokawa G, Goto Y, Nonogi H and Iwai N: Plasma microRNA 499 as a biomarker of acute myocardial infarction. Clin Chem 56: 1183-1185, 2010.

12. Condorelli G, Latronico MV and Cavarretta E: microRNAs in cardiovascular diseases. J Am Coll Cardiol 63: 2177-2187, 2014.

13. Gao LB, Bai P, Pan XM, Jia J, Li LJ, Liang WB, Tang M, Zhang LS, Wei YG and Zhang L: The association between two polymorphisms in pre-miRNAs and breast cancer risk: A meta-analysis. Breast Cancer Res Treat 125: 571-574, 2011.

14. Hu Z, Liang J, Wang Z, Tian T, Zhou X, Chen J, Miao R, Wang Y, Wang $\mathrm{X}$ and Shen $\mathrm{H}$ : Common genetic variants in pre-microRNAs were associated with increased risk of breast cancer in Chinese women. Hum Mutat 30: 79-84, 2009.

15. Tian T, Shu Y, Chen J, Hu Z, Xu L, Jin G, Liang J, Liu P, Zhou X, Miao R, et al: A functional genetic variant in microRNA-196a2 is associated with increased susceptibility of lung cancer in Chinese. Cancer Epidemiol Biomark Prev 18: 1183-1187, 2009.

16. Xu J, Hu Z, Xu Z, Gu H, Yi L, Cao H, Chen J, Tian T, Liang J, Lin Y, et al: Functional variant in microRNA-196a 2 contributes to the susceptibility of congenital heart disease in a Chinese population. Hum Mutat 30: 1231-1236, 2009.

17. Min KT, Kim JW, Jeon YJ, Jang MJ, Chong SY, Oh D and Kim NK: Association of the miR-146aC $>$ G, 149C $>$ T, 196a2C $>$ T, and $499 \mathrm{~A}>\mathrm{G}$ polymorphisms with colorectal cancer in the Korean population. Mol Carcinog 51 (Suppl 1): E65-E73, 2012.

18. Park YS, Jeon YJ, Lee BE, Kim TG, Choi JU, Kim DS and Kim NK: Association of the miR-146aC $>$ G, miR-196a2C $>$ T, and miR-499A $>$ G polymorphisms with moyamoya disease in the Korean population. Neurosci Lett 521: 71-75, 2012.

19. Wang AX, Xu B, Tong N, Chen SQ, Yang Y, Zhang XW, Jiang H, Liu N, Liu J, Hu XN, et al: Meta-analysis confirms that a common $\mathrm{G} / \mathrm{C}$ variant in the pre-miR-146a gene contributes to cancer susceptibility and that ethnicity, gender and smoking status are risk factors. Genet Mol Res 11: 3051-3062, 2012.

20. Ahn DH, Rah H, Choi YK, Jeon YJ, Min KT, Kwack K, Hong SP, Hwang SG and Kim NK: Association of the miR-146aC $>$ G, miR-149T $>$ C, miR-196a2T $>C$, and miR-499A $>$ G polymorphisms with gastric cancer risk and survival in the Korean population. Mol Carcinog 52 (Suppl 1): E39-E51, 2013.

21. Jeon YJ, Choi YS, Rah H, Kim SY, Choi DH, Cha SH, Shin JE, Shim SH, Lee WS and Kim NK: Association study of microRNA polymorphisms with risk of idiopathic recurrent spontaneous abortion in Korean women. Gene 494: 168-173, 2012.

22. Bhartiya D, Laddha SV, Mukhopadhyay A and Scaria V: miRvar: A comprehensive database for genomic variations in microRNAs. Hum Mutat 32: E2226-E2245, 2011.

23. Ryan BM, Robles AI and Harris CC: Genetic variation in microRNA networks: The implications for cancer research. Nat Rev Cancer 10: 389-402, 2010.

24. Hua L, Xia H, Zhou P, Li D and Li L: Combination of microRNA expression profiling with genome-wide SNP genotyping to construct a coronary artery disease-related miRNA-miRNA synergistic network. Biosci Trends 8: 297-307, 2014.

25. Ritchie MD, Hahn LW, Roodi N, Bailey LR, Dupont WD, Parl FF and Moore JH: Multifactor dimensionality reduction reveals high-order interactions among estrogen-metabolism genes in sporadic breast cancer. Am J Hum Genet 69: 138-147, 2001.

26. Hahn LW, Ritchie MD and Moore JH: Multifactor dimensionality reduction software for detecting gene-gene and environment interactions. Bioinformatics 19: 376-382, 2003.

27. Carissimi C, Fulci V and Macino G: MicroRNAs: Novel regulators of immunity. Autoimmun Rev 8: 520-524, 2009. 
28. Duan R, Pak C and Jin P: Single nucleotide polymorphism associated with mature miR-125a alters the processing of pri-miRNA. Hum Mol Genet 16: 1124-1131, 2007.

29. Jiang S, Chen Q, Venners SA, Zhong G, Hsu YH, Xing H, Wang X and Xu X: Effect of simvastatin on plasma homocysteine levels and its modification by MTHFR C677T polymorphism in Chinese patients with primary hyperlipidemia. Cardiovasc Ther 31: e27-e33, 2013.

30. Lobo SM, Quinto BM, Oyama L, Nakamichi R, Ribeiro AB, Zanella MT, Dalboni MA and Batista MC: TNF- $\alpha$ modulates statin effects on secretion and expression of MCP-1, PAI-1 and adiponectin in 3T3-L1 differentiated adipocytes. Cytokine 60: 150-156, 2012.

31. Fichtlscherer S, De Rosa S, Fox H, Schwietz T, Fischer A, Liebetrau C, Weber M, Hamm CW, Röxe T, Müller-Ardogan M, et al: Circulating microRNAs in patients with coronary artery disease. Circ Res 107 677-684, 2010.

32. Laterza OF, Lim L, Garrett-Engele PW, Vlasakova K, Muniappa N, Tanaka WK, Johnson JM, Sina JF, Fare TL, Sistare FD and Glaab WE: Plasma microRNAs as sensitive and specific biomarkers of tissue injury. Clin Chem 55: 1977-1983, 2009.

33. Li S, Zhu J, Zhang W, Chen Y, Zhang K, Popescu LM, Ma X, Lau WB, Rong R, Yu X, et al: Signature microRNA expression profile of essential hypertension and its novel link to human cytomegalovirus infection. Circulation 124: 175-184, 2011

34. Tan KS, Armugam A, Sepramaniam S, Lim KY, Setyowati KD, Wang CW and Jeyaseelan K: Expression profile of microRNAs in young stroke patients. PLoS One 4: e7689, 2009.

35. Lujambio A, Ropero S, Ballestar E, Fraga MF, Cerrato C, Setién F, Casado S, Suarez-Gauthier A, Sanchez-Cespedes M, Git A, et al: Genetic unmasking of an epigenetically silenced microRNA in human cancer cells. Cancer Res 67: 1424-1429, 2007.

36. El Gazzar M, Church A, Liu T and McCall CE: MicroRNA-146a regulates both transcription silencing and translation disruption of TNF- $\alpha$ during TLR4-induced gene reprogramming. J Leukoc Biol 90: 509-519, 2011.

37. Luthra R, Singh RR, Luthra MG, Li YX, Hannah C, Romans AM, Barkoh BA, Chen SS, Ensor J, Maru DM, et al: MicroRNA-196a targets annexin A1: A microRNA-mediated mechanism of annexin A1 downregulation in cancers. Oncogene 27: 6667-6678, 2008
38. Cui G, Wang H, Li R, Zhang L, Li Z, Wang Y, Hui R, Ding $\mathrm{H}$ and Wang D: Polymorphism of tumor necrosis factor alpha (TNF-alpha) gene promoter, circulating TNF-alpha level and cardiovascular risk factor for ischemic stroke. J Neuroinflammation 9: 235, 2012.

39. Solito E, McArthur S, Christian H, Gavins F, Buckingham JC and Gillies GE: Annexin A1 in the brain-undiscovered roles? Trends Pharmacol Sci 29: 135-142, 2008.

40. Tsai NW, Lee LH, Huang CR, Chang WN, Chen SD, Wang HC, Lin YJ, Lin WC, Chiang YF, Lin TK, et al: The association of statin therapy and high-sensitivity $\mathrm{C}$-reactive protein level for predicting clinical outcome in acute non-cardioembolic ischemic stroke. Clin Chim Acta 413: 1861-1865, 2012.

41. Yang YH, Aeberli D, Dacumos A, Xue JR and Morand EF: Annexin-1 regulates macrophage IL- 6 and TNF via glucocorticoid-induced leucine zipper. J Immunol 183: 1435-1445, 2009.

42. Wessel J, Moratorio G, Rao F, Mahata M, Zhang L, Greene W, Rana BK, Kennedy BP, Khandrika S, Huang P, et al: C-reactive protein, an intermediate phenotype' for inflammation: Human twin studies reveal heritability, association with blood pressure and the metabolic syndrome, and the influence of common polymorphism at catecholaminergic/beta-adrenergic pathway loci. J Hypertens 25: 329-343, 2007.

43. Calcagni E and Elenkov I: Stress system activity, innate and $\mathrm{T}$ helper cytokines and susceptibility to immune-related diseases. Ann N Y Acad Sci 1069: 62-76, 2006.

44. Hoffman AE, Zheng T, Yi C, Leaderer D, Weidhaas J, Slack F, Zhang Y, Paranjape T and Zhu Y: microRNA miR-196a-2 and breast cancer: A genetic and epigenetic association study and functional analysis. Cancer Res 69: 5970-5977, 2009.

45. Shen J, Ambrosone CB, DiCioccio RA, Odunsi K, Lele SB and Zhao $\mathrm{H}$ : A functional polymorphism in the miR-146a gene and age of familial breast/ovarian cancer diagnosis. Carcinogenesis 29: 1963-1966, 2008.

46. Yang B, Chen J, Li Y, Zhang J, Li D, Huang Z, Cai B, Li L, Shi Y, Ying B and Wang L: Association of polymorphisms in pre-miRNA with inflammatory biomarkers in rheumatoid arthritis in the Chinese Han population. Hum Immunol 73: 101-106, 2012 